\section{Dr. Weinstein replies}

\section{To the Editor:}

Dr. Andrés and colleagues report an interesting case of clinically significant axial gout quickly responsive to prednisone therapy ${ }^{1}$. We previously described that axial gout is often asymptomatic ${ }^{2}$, but this case demonstrates the importance of recognizing a clinical gouty flare in the spine because of the effectiveness of therapy for the crystal-induced inflammation. This case also points out the superiority of computed tomography compared to magnetic resonance imaging in the diagnosis of axial gout. It is of interest that simultaneous active gout in the appendicular joints is not described in this patient, making it even more imperative to consider the diagnosis of spinal gout in a patient with chronic gout, especially in those patients with clinical and radiological evidence of chronic gouty arthropathy in the hands or feet ${ }^{2}$.
ARTHUR WEINSTEIN, MD, FACP, FRCP, MACR, Professor of Medicine, Georgetown University Medical Center; Chief, Division of

Rheumatology, Washington Hospital Center, Washington, DC, USA.

Address correspondence to Dr. A. Weinstein, Division of Rheumatology, Suite 2A-66, Washington Hospital Center, 110 Irving Street NW,

Washington, DC 20010, USA. E-mail: arthur.weinstein@MedStar.net

\section{REFERENCES}

1. Andrés M, Vela P, Volar LC, Avilés Y, Pascual E. Back pain due to lumbar gouty flare - A prospective diagnosis [letter]. J Rheumatol 2013;40:1459-60.

2. Konatalapalli RM, Lumezanu E, Jelinek JS, Murphey MD, Wang $\mathrm{H}$, Weinstein A. Correlates of axial gout: A cross-sectional study. J Rheumatol 2012;39:1445-9.

J Rheumatol 2013;40:8; doi:10.3899/jrheum.130373 